\title{
SUSCETIBILIDADE AO ENTUPIMENTO DE GOTEJADORES APLICANDO ÁGUA RESIDUÁRIA DOMÉSTICA TRATADA
}

\author{
Danniely de Oliveira Costa* \\ Hudson Salatiel Marques Vale ${ }^{* *}$ \\ Rafael Oliveira Batista*** \\ Paulo César Moura da Silva**** \\ Luis César de Aquino Lemos Filho****** \\ Delfran Batista dos Santos******
}

RESUMO: Objetivou-se com este trabalho analisar as alterações do desempenho hidráulico de distintos modelos de gotejadores que operaram com água residuária doméstica tratada, bem como obter modelos empíricos em função da variável tempo de operação e qualidade do efluente. Para isso, montou-se um experimento na Universidade Federal Rural do Semi-Árido (UFERSA) composto por quatro unidades de irrigação, dotadas de três tipos de gotejadores (Plastro Hydrodrip Super, Netafim Tiran e Netafim PCJ-CNJ), em três repetições (três linhas laterais por tipo de gotejador). A cada 80 horas de operação do sistema com água residuária doméstica tratada determinaram-se os valores do coeficiente de variação vazão (CVQ) e redução da vazão relativa $(\mathrm{RQR})$ e as características física, químicas e microbiológicas do efluente, até completar o tempo de operação de 400 horas. Os dados foram submetidos às análises de regressão simples e linear múltipla. $\mathrm{O}$ gotejador G1 apresentou maiores alterações no desempenho hidráulico, sendo mais suscetivel ao entupimento do que os gotejadores Netafim Tiran e Netafim PCJ-CNJ. Os modelos de regressão nulo e raiz quadrada foram os que melhor explicaram

\footnotetext{
"Doutora em Manejo de Solo e Água da Universidade Federal Rural do Semi-Árido - UFERSA campus Mossoró, RN, Brasil.

** Doutor em Manejo de Solo e Água da Universidade Federal Rural do Semi-Árido - UFERSA campus Mossoró, RN, Brasil.

**** Doutor em Engenharia Agrícola da Universidade Federal de Viçosa - UFV, Docente permanente do Programa de Pós-graduação em Manejo de Solo e Água da Universidade Federal Rural do Semi-Árido - UFERSA campus Mossoró, RN, Brasil. E-mail: rafaelbatista@ufersa.edu.br

***** Doutor em Recursos Naturais da Universidade Federal de Campina Grande - UFCG, Docente permanente do Curso de Especialização em Geoprocessamento e Georreferenciamento da Universidade Federal Rural do Semi-Árido - UFERSA campus Mossoró, RN, Brasil.

****** Doutor em Engenharia Agrícola da Universidade Federal de Lavras - UFLA, Docente permanente do Programa de Pós-graduação em Manejo de Solo e Água da Universidade Federal Rural do Semi-Árido - UFERSA campus Mossoró, RN, Brasil.

******* Doutor em Engenharia Agrícola da Universidade Federal de Lavras - UFLA, Docente efetivo do Instituto Federal Baiano - IFBAIANO campus Salvador, BA, Brasil.
} 
a relação entre as variáveis CVQ e RQR e o tempo de operação das unidades de irrigação. As características $\mathrm{pH}, \mathrm{SS}, \mathrm{SD}, \mathrm{Fe}, \mathrm{Mg}^{2+}$ e CT predominaram nos modelos empíricos de desempenho hidráulico para os três tipos de gotejadores.

PALAVRAS-CHAVE: Emissores; Obstrução; Vazão.

\title{
SUSCEPTIBILITY OF CLOGGING OF DRIPPERS WHEN DOMESTIC HOME RESIDUAL WATER IS APPLIED
}

\begin{abstract}
Changes in the hydraulic performance of distinct models of drippers with treated domestic water are analyzed, coupled to empirical models for the variable operation time and effluent quality. An experiment, elaborated at the Universidade Federal Rural do Semi-Árido (UFERSA), comprised four irrigation units with three types of drippers (Plastro Hydrodrip Super, Netafim Tiran and Netafim PCJ-CNJ), with three replications (three lateral lines per dripper type). The coefficient rates of discharge variation and the reduction of relative discharge were determined every $80 \mathrm{~h}$ of operation with treated domestic residual water, coupled to physical, chemical and microbiological characteristics of the effluent till the completion of 400 h. Data underwent simple regression and multiple linear analyses. Dripper G1 had the greatest changes in hydraulic performance and was more liable to clogging than drippers Netafim Tiran and Netafim PCJ-CNJ. Nil and square root regression models best explained the relationship between variables $C V Q$ and $R Q R$ and operation time of the irrigation units. Further, $\mathrm{pH}, \mathrm{SS}, \mathrm{SD}, \mathrm{Fe}, \mathrm{Mg} 2+$ and CT predominated in empirical models for hydraulic performance for the three dripper types.
\end{abstract}

KEY WORDS: Drippers; Obstruction; Discharge.

\section{INTRODUÇÃO}

A irrigação localizada se destaca para aplicação de águas residuárias em relação aos demais métodos de irrigação, em virtude da não geração de aerossóis que contaminam o ambiente e da minimização da contaminação de águas subterrâneas (TRIPATHI; RAJPUT; PATEL, 2016).

Segundo Freitas et al. (2015), na irrigação localizada a água é aplicada de forma pontual e não aspergida, evitando o contato direto da água residuária com o irrigante e produtos agrícolas. Porém, seus emissores estão entre as peças mais 
importantes do sistema, possuindo um estreito labirinto que facilmente pode ser obstruído por poluentes, tais como partículas em suspensão, precipitações químicas, matéria orgânica e microrganismos (SONG et al., 2017).

Diversos estudos com unidades gotejadoras aplicando águas residuárias comprovaram que a formação de biofilme no interior dos emissores e das linhas laterais é o principal obstáculo da localizada (BATISTA et al., 2016; CARMO et al., 2016; COSTA et al., 2016; CUNHA et al., 2017).

Batista et al. (2013) apontam que o fator central de entupimento de gotejadores tem sido a formação de depósitos gelatinosos resultantes da interação entre partículas orgânicas e inorgânicas, algas e bactérias formadoras de mucilagens.

A manutenção de elevada uniformidade de aplicação e distribuição de água nos sistemas de irrigação por gotejamento torna-se fundamental para uma eficiente irrigação e, consequentemente, um melhor aproveitamento dos recursos hídricos e redução dos custos (RIBEIRO et al., 2012).

Cararo et al. (2006) constataram redução de 5 a $28 \%$ nos valores do coeficiente de variação de vazão (CVQ) em 15 tipos de gotejadores testados com esgoto doméstico tratado durante 373 horas. O efluente passou por filtros de areia (com tamanho efetivo de 0,59 mm), de discos (com aberturas de $100 \mu \mathrm{m}$ ) e de tela (com aberturas de $80 \mu \mathrm{m}$ ) em série, antes de ser aplicado pelos gotejadores.

Para Fernandes et al. (2014) o grande problema associado à utilização de águas residuárias consiste na redução na vazão das unidades de irrigação, devido ao entupimento parcial ou total dos gotejadores. Batista et al. (2011) verificaram reduções de 62, 22 e 61\% na vazão dos gotejadores dos conjuntos de irrigação abastecidos com esgotos domésticos preliminar, secundário e terciário, respectivamente, após 500 horas de operação do sistema.

Neste sentido, o presente trabalho objetivou analisar as alterações do desempenho hidráulico de distintos modelos de gotejadores que operaram com água residuária doméstica tratada, bem como obter modelos empíricos em função da variável tempo de operação e qualidade do efluente. 


\section{MATERIAL E MÉTODOS}

O experimento foi realizado no período de 18 de março a 14 de maio de 2014, na Unidade Experimental de Reúso de Água (UERA) localizada na Universidade Federal Rural do Semi-Árido (UFERSA), em Mossoró (RN), sob as coordenadas geográficas de $5^{\circ} 12^{\prime} 27^{\prime \prime}$ de latitude Sul, $37^{\circ} 19^{\prime} 21$ ” de longitude Oeste, com altitude média de $18 \mathrm{~m}$. O clima da região, na classificação de Köppen, é do tipo BSwh (quente e seco), com precipitação pluviométrica bastante irregular, média anual de $673,9 \mathrm{~mm}$; temperatura de $27^{\circ} \mathrm{C}$ e umidade relativa do ar média de $68,9 \%$ (ALVARES et al., 2013).

A água residuária de origem doméstica foi coletada na Estação de Tratamento de Efluentes (ETE), gerenciada pela empresa Imunizadora Oeste LTDA. A sede administrativa da empresa está situada na Rua Juvenal Lamartine, Bairro Centro, Mossoró (RN).

Para realização dos ensaios foi montada uma bancada experimental em alvenaria na UERA com dois metros de largura por oito metros de comprimento, dotada de piso impermeabilizado e possuindo uma canaleta com declividade de $2 \%$, construída ao longo da lateral da bancada, para recirculação da água residuária doméstica tratada visando à minimização das perdas por evaporação. À jusante desta bancada foi construído um reservatório em alvenaria, para armazenar o efluente, com capacidade para $5 \mathrm{~m}^{3}$.

A bancada experimental foi composta por quatro unidades de irrigação por gotejamento, um conjunto motobomba de $1 \mathrm{cv}$, um filtro de tela com abertura de $130 \mu \mathrm{m}$, e um hidrômetro com capacidade para $1,5 \mathrm{~m}^{3}$. Cada unidade de irrigação apresentava um registro de gaveta e um manômetro analógico de glicerina da marca GE CI2.5, graduado de 0 a $400 \mathrm{kPa}$, para regulagem da pressão; uma linha de derivação de PVC com diâmetro nominal de $32 \mathrm{~mm}$ com nove conectores, para inserção de nove linhas laterais de polietileno com oito metros de comprimento, totalizando 36 linhas laterais em toda a bancada (Figura 1). 


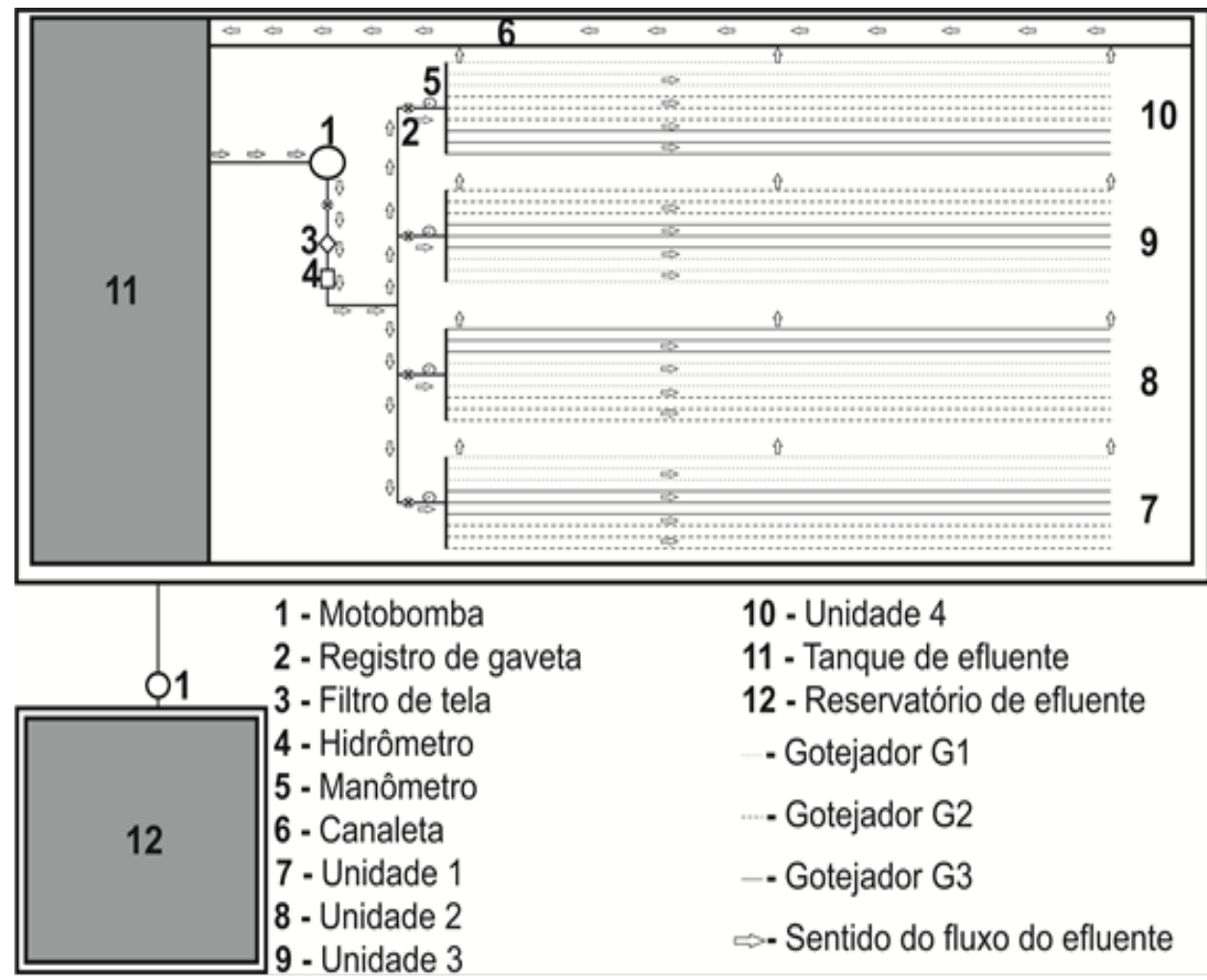

Figura 1. Esquema da bancada experimental apresentando o posicionamento dos reservatórios de efluente e das unidades de irrigação por gotejamento

Em cada unidade de irrigação foram testados três tipos de gotejadores, sendo suas características obtidas de catálogos técnicos fornecidos pelos fabricantes e medidas com o auxílio de paquímetro, conforme apresentadas na Tabela 1. 
Tabela 1. Gotejadores $(\mathrm{G})$ utilizados nos ensaios experimentais, destacando o fabricante (F), o dispositivo de autocompensação (DA), a vazão nominal (Q), o coeficiente de vazão (k), o expoente da vazão que caracteriza o regime de escoamento (x), a área de filtragem (A), o comprimento do labirinto (L), o coeficiente de variação de fabricação (CVf), a faixa de pressão recomendada (P) e o espaçamento entre emissores (EE)

\begin{tabular}{l|l|c|c|c|c|c|c|c|c|c}
\hline $\mathbf{G}$ & $\mathbf{F}$ & $\mathbf{D A}$ & $\begin{array}{c}\mathbf{Q}^{*} \\
\left(\mathbf{L ~ h}^{-1}\right)\end{array}$ & $\mathbf{k}^{*}$ & $\mathbf{x}^{*}$ & $\begin{array}{c}\mathbf{A} \\
\left(\mathbf{m m}^{2}\right)\end{array}$ & $\begin{array}{c}\mathbf{L} \\
(\mathbf{m m})\end{array}$ & $\begin{array}{c}\mathbf{C V}_{\mathbf{f}}^{*} \\
(\mathbf{\%})\end{array}$ & $\begin{array}{c}\mathbf{P} * \\
(\mathbf{k P a})\end{array}$ & $\begin{array}{c}\mathbf{E E}^{*} \\
(\mathbf{m})\end{array}$ \\
\hline G1 & $\begin{array}{l}\text { Plastro Hydro- } \\
\text { drip Super }\end{array}$ & Não & 1,65 & 0,53 & 0,48 & $4,0^{* *}$ & $37^{* *}$ & \pm 5 & $60-50$ & 0,30 \\
\hline G2 & Netafim Tiran & Não & 2,00 & 0,69 & 0,46 & $70,0^{*}$ & $75^{*}$ & \pm 7 & $\begin{array}{c}100- \\
300\end{array}$ & 0,40 \\
\hline G3 & Netafim PCJ-CNJ & Sim & 2,00 & 2,00 & 0,00 & $2,0^{*}$ & $35^{*}$ & \pm 7 & $50-400$ & 0,70 \\
\hline
\end{tabular}

Nota: * e ** informações obtidas nos catálogos dos fabricantes e informações medidas com auxílio de um parquímetro digital com precisão de $0,01 \mathrm{~mm}$, respectivamente. $\mathrm{CNJ}$ - sistema anti-drenante.

O desempenho hidráulico das unidades de irrigação foi realizado determinando-se a vazão dos gotejadores, em dez posições equidistantes de todas as linhas laterais. Os dados de vazão foram obtidos coletando-se o volume aplicado pelo emissor, durante um período de três minutos.

Os indicadores de desempenho hidráulico utilizados na detecção dos níveis de obstrução dos gotejadores nas unidades de irrigação foram: coeficiente de variação de vazão (CVQ) e redução da vazão relativa (RQR), conforme as Equações 1 e 2 , respectivamente. Estes indicadores foram determinados a cada 80 horas de operação das unidades de irrigação, sendo os períodos de operação inicial e final de 0 e 400 horas, respectivamente.

A nOrma ASAE EP 405 (AMERICAN SOCIETY FOR AGRICULTURAL ENGINEERIN, 2008) sugere a seguinte classificação para os valores do CVQ: menor que $10 \%$, bom; entre 10 e $20 \%$, razoável; e maior que $20 \%$, inaceitável.

$$
C V Q=100 \cdot \frac{\sqrt{\frac{\sum_{i=1}^{n}\left(q_{i}-\bar{q}\right)^{2}}{n_{e}-1}}}{\bar{q}}
$$


em que:

CVQ - coeficiente de variação da vazão, \%;

$\mathrm{q}_{\mathrm{i}}$ - vazão de cada gotejador, $\mathrm{L} \mathrm{h}^{-1}$;

q - vazão média dos gotejadores, $\mathrm{L} \mathrm{h}^{-1}$; e

$\mathrm{n}_{\mathrm{e}}$ - número de gotejadores avaliados.

Já o coeficiente de redução da vazão relativa (RQR) expressa o grau de entupimento do gotejador. De acordo com Capra e Scicolone (1998) o RQR pode ser classificado como alto (maior que 79\%), médio (entre 61 a $79 \%$ ) e baixo (menor que $61 \%)$.

$R Q R=100 \cdot\left(\frac{q_{i}-q_{a}}{q_{i}}\right)$

em que:

RQR - Redução da vazão relativa, \%;

$\mathrm{q}_{\mathrm{i}}$ - vazão inicial, $\mathrm{L} \mathrm{h}^{-1} ; \mathrm{e}$

$\mathrm{q}_{\mathrm{a}}$ - vazão atual, $\mathrm{L} \mathrm{h}^{-1}$.

As unidades de irrigação por gotejamento funcionaram, em média, oito horas por dia até completar o tempo de funcionamento de 400 horas, para potencializar a formação da bioincrustação nos gotejadores e nas linhas laterais.

Com o auxílio de registros de gaveta e manômetros analógicos com glicerina, graduados de 0 a $400 \mathrm{kPa}$, a pressão de serviço foi mantida em $100 \mathrm{kPa}$, para obter os valores de vazões nominais nos gotejadores ensaiados. No tempo de operação inicial $(0 \mathrm{~h})$, quando não houve obstrução, as variações de vazão entre os gotejadores encontraram-se na faixa de $\pm 7 \%$ assim como o coeficiente de variação de fabricação (CVf) da amostra não excedeu a $\pm 7 \%$, conforme os critérios estabelecidos pela NBR ISO 9261 (ABNT, 2006).

Efetuaram-se seis amostragens da água residuária doméstica tratada durante o período experimental para realização das análises físicas, químicas e microbiológicas, como mostradas na Tabela 2, as quais seguiram as recomendações do Standard Methods for the Examination of Water and Wastewater (RICE; BAIRD; CLESCERI, 2012). 
Tabela 2. Características físicas, químicas e microbiológicas da água residuária doméstica tratada, ao longo do tempo de operação das unidades de irrigação por gotejamento

\begin{tabular}{lcccccc}
\hline \multirow{2}{*}{ Características } & \multicolumn{7}{c}{ Tempo de operação (h) } \\
& $\mathbf{0}$ & $\mathbf{8 0}$ & $\mathbf{1 6 0}$ & $\mathbf{2 4 0}$ & $\mathbf{3 2 0}$ & $\mathbf{4 0 0}$ \\
\hline $\mathrm{DBO}$ & 163 & 19 & 23 & 48 & 10 & 15 \\
$\mathrm{DQO}$ & 713 & 130 & 264 & 349 & 137 & 161 \\
$\mathrm{pH}$ & 7,74 & 7,82 & 7,85 & 7,74 & 8,15 & 8,37 \\
$\mathrm{CE}$ & 4,05 & 3,54 & 3,32 & 5,28 & 5,37 & 5,40 \\
$\mathrm{SS}$ & 106 & 76 & 110 & 87 & 116 & 98 \\
$\mathrm{SD}$ & 3321 & 2655 & 2490 & 4330 & 4403 & 4428 \\
$\mathrm{Fe}$ & 0,25 & 0,26 & 0,29 & 0,30 & 0,42 & 0,52 \\
$\mathrm{Mn}$ & 0,11 & 0,10 & 0,12 & 0,16 & 0,14 & 0,20 \\
$\mathrm{Ca}{ }^{2+}$ & 5,20 & 4,20 & 4,40 & 7,20 & 6,50 & 6,40 \\
$\mathrm{Mg}{ }^{2+}$ & 1,80 & 0,80 & 2,40 & 2,30 & 2,80 & 2,70 \\
$\mathrm{~K}$ & 7,60 & 5,60 & 9,00 & 6,30 & 6,20 & 6,10 \\
$\mathrm{Na}$ & 9,50 & 8,90 & 8,30 & 9,60 & 7,50 & 7,60 \\
$\mathrm{Dur}$ & 350 & 250 & 340 & 475 & 465 & 470 \\
$\mathrm{RAS}$ & 5,08 & 5,63 & 4,50 & 4,40 & 3,48 & 3,50 \\
$\mathrm{Bh}$ & 100 & 500 & 200 & 250 & 100 & 60 \\
$\mathrm{CTe}$ & 40 & 4000 & 300 & 500 & 300 & 200 \\
$\mathrm{CT}$ & 1000 & 7000 & 1500 & 1600 & 1200 & 800 \\
\hline
\end{tabular}

Nota: DBO - demanda bioquímica de oxigênio, $\mathrm{mg} \mathrm{L} \mathrm{L}^{-1} ; \mathrm{DQO}$ - demanda química de oxigênio, $\mathrm{mg} \mathrm{L}^{-1} ; \mathrm{pH}$ - poten-

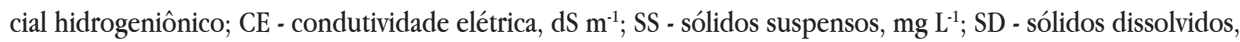
$\mathrm{mg} \mathrm{L}^{-1} ; \mathrm{Fe}$ - ferro, $\mathrm{mg} \mathrm{L}^{-1} ; \mathrm{Mn}$ - manganês, $\mathrm{mg} \mathrm{L}^{-1} ; \mathrm{Ca}^{2+}$ - cálcio, mmol $\mathrm{L}_{\mathrm{c}}^{-1} ; \mathrm{Mg}^{2+}$ - magnésio, $\mathrm{mmol}_{\mathrm{c}} \mathrm{L}^{-1} ; \mathrm{K}^{+}$- potássio, mmol $\mathrm{L}^{-1} ; \mathrm{Na}^{+}$- sódio, mmol $\mathrm{L}^{-1}$; Dur - dureza, $\mathrm{mg} \mathrm{L}^{-1} ; \mathrm{RAS}$ - razão de adsorção de sódio, $\left(\mathrm{mmol}_{\mathrm{c}} \mathrm{L}^{-1}\right)^{0,5}$; Bh - bactérias heterotróficas, UFC $\mathrm{mL}^{-1}$; CTe - coliformes termotolerantes, UFC $100 \mathrm{~mL}^{-1}$; CT - coliformes totais, UFC $100 \mathrm{~mL}^{-1}$; e UFC - unidades formadoras de colônias.

As médias foram comparadas empregando-se o teste de Tukey a 5\% de probabilidade. Os modelos de regressão simples e múltipla foram escolhidos com base na significância dos coeficientes de regressão, aplicando-se o teste t em um nível de até $10 \%$, no coeficiente de determinação ( $\geq 60 \%)$ e no processo em estudo. 


\section{RESULTADOS E DISCUSSÃO}

No Gráfico 1 estão representados os valores médios de CVQ e RQR, ao longo do período de operação, nas unidades de irrigação dotadas dos três tipos de gotejadores.

A

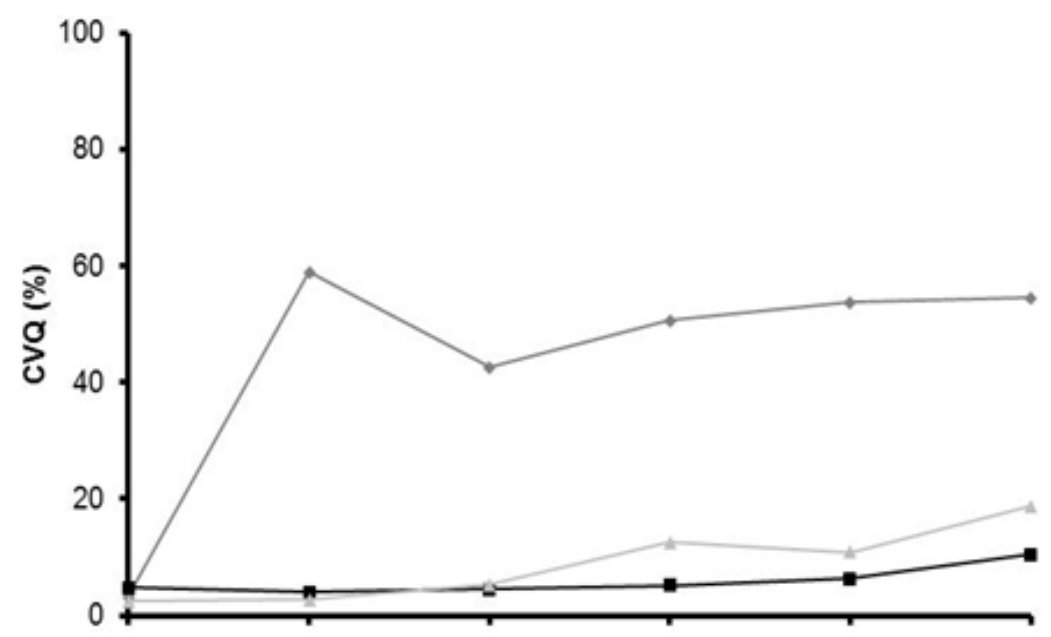

$\mathrm{B}$
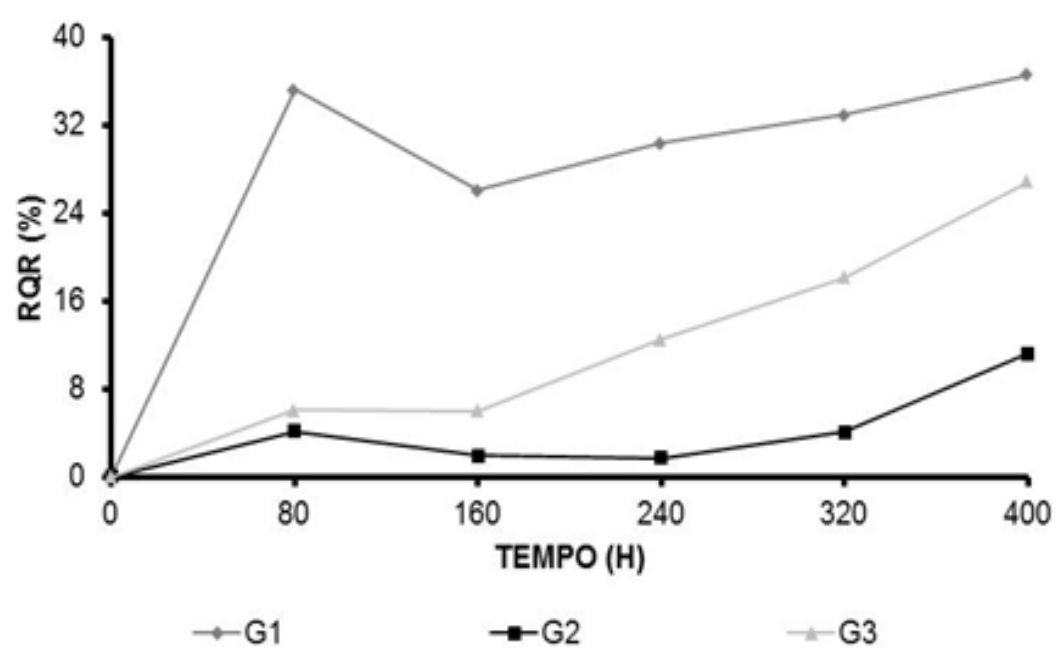

$-\mathrm{G} 3$

Gráfico 1. Valores médios de CVQ (A) e RQR (B), durante 400 horas de operação do sistema, nas unidades de irrigação dotadas dos três tipos de gotejadores (G1, G2 e G3) 
Observa-se, conforme o Gráfico 1A, que os valores médios do CVQ nas unidades de irrigação, para os tempos de operação inicial $(0$ h) e final (400 horas), foram de 3 e $54 \%$ para o gotejador G1, de 5 e 10\% para o gotejador G2 e de 2 e $19 \%$ para o gotejador $\mathrm{G} 3$, respectivamente.

Nos resultados encontrados por Silva et al. (2013), o gotejador G1 (1,6 L $\mathrm{h}^{-1}$ ) das unidades de irrigação submetidas às pressões de serviço 70, 140, 210 e 280 $\mathrm{kPa}$, nos tempos de funcionamento inicial e 160 horas, apresentaram valores de CVQ de 5 e $44 \%$; 3 e $5 \%$; 6 e $7 \%$; e 5 e $2 \%$, respectivamente.

De acordo com a norma ASAE EP 405 (AMERICAN SOCIETY FOR AGRICULTURAL ENGINEERIN, 2008), os valores médios do CVQ nas unidades de irrigação, para o tempo de operação de 400 horas, foram classificados como inaceitáveis (> 20\%) para o gotejador G1 e como razoáveis (entre 10 e 20\%) para os gotejadores G2 e G3.

Silva et al. (2013) verificaram, no tempo de funcionamento de 160 horas, que o valor de CVQ da unidade de irrigação submetida à pressão de serviço de $70 \mathrm{kPa}$ foi superior a 20\%, recebendo, assim, a classificação inaceitável, segundo a norma ASABE EP 405 (AMERICAN SOCIETY FOR AGRICULTURAL ENGINEERIN, 2008).

Com relação ao RQR (Gráfico $1 B)$ verificou-se que, no tempo inicial $(0 \mathrm{~h})$, os valores médios foram iguais a zero, visto que, nesse instante, a vazão atual foi idêntica à vazão inicial. Já no tempo de operação final ( 400 horas), os valores médios do RQR nas unidades de irrigação foram de 37, 11 e 27\% para os gotejadores G1, G2 e G3, respectivamente.

Avaliando o entupimento de gotejadores em função da aplicação de carbonato de potássio, Medeiros et al. (2008) obtiveram, ao final do experimento, valores do RQR iguais a 52 e $17 \%$ para dois tipos de gotejadores, M1 $\left(1,4 \mathrm{~L} \mathrm{~h}^{-1}\right)$ e M2 $\left(2,05 \mathrm{~L} \mathrm{~h}^{-1}\right)$, respectivamente.

Conforme Capra e Scicolone (1998), os valores médios do RQR nas unidades de irrigação, para o tempo de operação de 400 horas, foram classificados como baixos (< 61\%) para os gotejadores G1, G2 e G3.

Em geral, observa-se para o gotejador G1 uma tendência de crescimento nos valores do CVQ e RQR, ao longo do tempo de operação do sistema. Isto indica que 
a suscetibilidade ao entupimento foi maior para este gotejador, quando comparado aos gotejadores G2 e G3.

Tal fato pode estar atribuído à menor vazão, ao menor comprimento do labirinto e à formação de bioincrustação, principalmente, na área de filtração e no interior do labirinto. Esses resultados são similares aos obtidos por Batista et al. (2013) e Batista, Oliveira e Mesquita (2014), onde a formação de biofilme foi maior no gotejador G1 $\left(2,0 \mathrm{~L} \mathrm{~h}^{-1}\right)$ em relação a $\mathrm{G} 2\left(1,7 \mathrm{~L} \mathrm{~h}^{-1}\right)$ e $\mathrm{G} 3\left(3,6 \mathrm{~L} \mathrm{~h}^{-1}\right)$, quando operados com distintos manejos de água residuária de suinocultura e de água de abastecimento.

Além disso, em estudo realizado por Carvalho et al. (2015), observou-se que o posicionamento para baixo dos orifícios dos emissores, como utilizado no presente estudo, propicia uma maior susceptibilidade ao entupimento, provavelmente devido ao processo de decantação dos agentes ocasionadores de obstrução no fundo do gotejador.

$\mathrm{Na}$ Tabela 3 estão apresentadas as equações de regressão ajustadas às variáveis CVQ e RQR, em função dos tempos de operação (T) das unidades de irrigação, para os gotejadores G1, G2 e G3.

Tabela 3. Equações de regressão ajustadas ao coeficiente de variação de vazão (CVQ) e ao coeficiente de redução da vazão relativa (RQR), em função dos tempos de operação (T) das unidades de irrigação, para os três tipos de gotejadores (G1, G2 e G3)

\begin{tabular}{clc}
\hline Gotejadores & Equação de regressão & $\mathbf{R}^{2}$ \\
$\mathrm{G} 1$ & $=5,504+6,398^{* *} \mathrm{~T}^{1 / 2}-0,207 * \mathrm{~T}$ & 0,60 \\
$\mathrm{G} 2$ & $=4,580+0,0000691 * * \mathrm{~T}^{2}-0,0138^{*} \mathrm{~T}$ & 0,72 \\
$\mathrm{G} 3$ & $==8,792$ & - \\
$\mathrm{G} 1$ & $=1,620+3,800^{* *} \mathrm{~T}^{1 / 2}-0,112 * \mathrm{~T}$ & 0,64 \\
$\mathrm{G} 2$ & $==3,917$ & - \\
$\mathrm{G} 3$ & $=-1,119+0,063 * * \mathrm{~T}$ & 0,84 \\
\hline
\end{tabular}

**, *, $\mathrm{e}^{0}$ significativos a 1,5 e $10 \%$ de probabilidade, respectivamente, pelo teste $\mathrm{t}$.

Com relação aos dados de CVQ, os modelos raiz quadrada, quadrático e nulo ajustaram-se melhor, em função dos tempos de operação (T) das unidades de irrigação, para os gotejadores G1, G2 e G3, respectivamente, sendo os valores de $\mathrm{R}^{2}$ iguais a 0,60 e 0,72 , respectivamente. 
Batista, Oliveira e Mesquita (2012) ajustaram o modelo nulo (média) à relação entre os dados de CVQ e T das unidades de irrigação dotadas de gotejador G1 $\left(2,0 \mathrm{~L} \mathrm{~h}^{-1}\right)$, operando com água residuária de suinocultura durante 160 horas.

O modelo raiz quadrada e linear foram os que melhor representaram a relação entre os dados de RQR e T para os gotejadores G1 e G3, respectivamente, obtendo $\mathrm{R}^{2}$ iguais a 0,64 e 0,84 . Para o gotejador $\mathrm{G} 2$, os valores de RQR não foram alterados, significativamente, por $\mathrm{T}$.

Avaliando o entupimento de emissores devido à aplicação de efluente de esgoto tratado, Liu e Huang (2009) obtiveram relação linear entre o RQR e a percentagem de gotejadores completamente entupidos para dois tipos de gotejadores E1 $\left(2,83 \mathrm{~L} \mathrm{~h}^{-1}\right)$ e E2 $\left(1,88 \mathrm{~L} \mathrm{~h}^{-1}\right)$, obtendo coeficientes de regressão $\left(\mathrm{R}^{2}\right)$ de 0,71 e 0,87 .

Na Tabela 4 estão apresentadas as equações de regressão linear múltipla, ajustadas às variáveis CVQ e RQR em função das características física (SS), químicas (SD, Fe e $\mathrm{Mg}^{2+}$ ) e biológica (CT) da água residuária doméstica tratada, para os gotejadores G1, G2 e G3 das unidades de irrigação.

Tabela 4. Equações de regressão ajustadas ao coeficiente de variação de vazão (CVQ) e ao coeficiente de redução da vazão relativa (RQR), em função das características física (SS), químicas $\left(\mathrm{SD}, \mathrm{Fe}, \mathrm{Mg}^{2+}\right.$ ) e biológica (CT) da água residuária doméstica tratada, para os três tipos de gotejadores (G1, G2 e G3)

\section{Gotejadores Equação de regressão}

$\begin{array}{llc}\text { G1 } & =361,397+40,734 * \mathrm{Mg}^{2+}+99,466 * \mathrm{CT} & 0,77 \\ \text { G2 } & =-1,574+21,908^{*} \mathrm{Fe} & 0,92 \\ \text { G3 } & =11,424-0,289 * \mathrm{SS}+29,541 * \mathrm{Fe}+7,432 * \mathrm{Mg}^{2+} & 1 \\ \text { G1 } & =-227,915+26,417 * \mathrm{Mg}^{2+}+61,926^{*} \mathrm{CT} & 0,70 \\ \text { G2 } & =5,847-0,115^{*} \mathrm{SS}-0,00184 * \mathrm{SD}+47,179^{*} \mathrm{Fe} & 1 \\ \text { G3 } & =0,465-0,246 * \mathrm{SS}+77,339 * \mathrm{Fe}+4,272^{0} \mathrm{Mg}^{2+} & 1\end{array}$

**, *, $\mathrm{e}^{0}$ significativos a 1,5 e $10 \%$ de probabilidade, respectivamente, pelo teste $\mathrm{t}$.

Para o gotejador G1, observou-se o efeito linear das características $\mathrm{Mg}^{2+} \mathrm{e}$ CT na alteração dos valores de CVQ e RQR, tendo coeficientes de determinação $\left(\mathrm{R}^{2}\right)$ iguais a 0,77 e 0,70 , respectivamente.

Em estudo realizado com sistemas de irrigação apresentando problemas 
de obstrução, Capra e Scicolone (1998) observaram, apenas, relações lineares simples dos teores de ferro e bicarbonato com o coeficiente de variação, devido ao desempenho de emissores no campo (CVdc).

Com relação ao gotejador G2, para a variável CVQ, houve relação linear em função, apenas, da característica Fe, tendo $R^{2}$ de 0,92 . Enquanto que, para a variável $\mathrm{RQR}$, foi notada relação linear entre as características SS, SD e Fe, apresentando $\mathrm{R}^{2}$ igual a 1 .

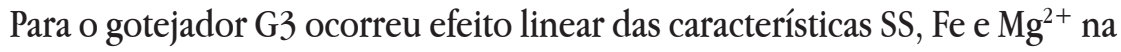
alteração dos valores de CVQ e RQR, possuindo $\mathrm{R}^{2}$ iguais a 1 .

Capra e Scicolone (1998) evidenciaram relações lineares simples entre as características sólidos suspensos, condutividade elétrica, ferro, cálcio e magnésio e os dados de RQR para sistemas de irrigação montados em campo.

\section{CONSIDERAÇÕES FINAIS}

O gotejador Plastro Hydrodrip Super apresentou maiores alterações no desempenho hidráulico, sendo mais suscetível ao entupimento do que os gotejadores Netafim Tiran e Netafim PCJ-CNJ.

Os modelos de regressão nulo e raiz quadrada foram os que melhor explicaram a relação entre as variáveis coeficiente de variação de vazão e redução da vazão relativa e o tempo de operação das unidades de irrigação.

As características $\mathrm{pH}$, sólidos suspensos, sólidos dissolvidos, ferro total, magnésio e coliformes totais predominaram nos modelos empíricos de desempenho hidráulico para os três tipos de gotejadores.

\section{REFERÊNCIAS}

ABNT. NBR ISO 9261: Equipamentos de irrigação agrícola - emissores e tubos emissores - especificações e métodos de ensaio. São Paulo: ABNT, 2006. 17 p.

ALVARES, C. A.; STAPE, J. L.; SENTELHAS, P. C.; GONÇALVES, J. L. de M.; 
SPAROVEK, G. Koppen's climate classification map for Brazil. Meteorologische Zeitschrift, v. 22, n. 6, p. 711-728, 2013.

AMERICAN SOCIETY FOR AGRICULTURAL ENGINEERIN. ASAE EP 405.1 APR1988 (R2008): design and installation of microirrigation systems. St. Joseph, USA: ASABE, 2008. 5 p.

BATISTA, R. O.; SOARES, A. A.; MOREIRA, D. A.; FEITOSA, A. P.; BEZERRA, J. M. Influência de diferentes qualidades de esgoto doméstico na vazão de gotejadores. Revista Caatinga, v. 24, n. 3, p. 128-134, 2011.

BATISTA, R. O.; OLIVEIRA, R. A.; MESQUITA, F. O. Desempenho hidráulico de sistema de irrigação por gotejamento aplicando água residuária de suinocultura. Revista Verde, v. 7, n. 4, p. 26-32, 2012.

BATISTA, R. O.; OLIVEIRA, R. A.; SANTOS, D. B.; OLIVEIRA, A. F. M.; AZEVEDO, C. A. V.; MEDEIROS, S. S. Obstrução e uniformidade de aplicação em sistemas de irrigação por gotejamento aplicando-se efluente da suinocultura. Revista Brasileira de Engenharia Agrícola e Ambiental, v. 17, n. 7, p. 698-705, 2013.

BATISTA, R. O.; OLIVEIRA, A. F. M.; MESQUITA, F. O. Desempenho hidráulico de sistemas de irrigação por gotejamento operando com água residuária da suinocultura. Magistra, v. 26, n. 1, p. 75-88, 2014.

BATISTA, R. O.; OLIVEIRA, R. A.; SANTOS, D. B.; CUNHA, F. F.; MEDEIROS, S. S. Modelos empíricos da aplicação de água residuária de suinocultura por gotejadores sob pressões de serviço. Irriga, v. 21, n. 4, p. 648-661, 2016.

CAPRA, A.; SCICOLONE, B. Water quality and distribution uniformity in drip/trickle irrigation systems. Journal of Agricultural Engineering Research, v. 70, n. 4, p. 355-365, 1998.

CARARO, D. C.; BOTREL, T. A.; HILLS, D. J.; LEVERENZ, H. L. Analysis of clogging in drip emitters during wastewater irrigation. Applied Engineering in Agriculture, v. 22, n. 2, p. 251-257, 2006.

CARMO, F. F.; DUTRA, I.; BATISTA, A. A.; BATISTA, R. O.; SILVA, M. G. Dimensiona- 
mento hidráulico e avaliação de um sistema de irrigação localizada de baixo custo. Engenharia na Agricultura, v. 24, n. 4, p. 302-313, 2016.

COSTA, D. O.; BATISTA, R. O.; VALE, H. S. M.; SOUSA, A. B.; DOMBROSKI, S. A. G. Biological treatment of drippers clogged by the use of treated domestic wastewater. Revista Brasileira de Engenharia Agrícola e Ambiental, v. 20, n. 7, p. 595-599, 2016.

CUNHA, M. E.; MARQUES, B. C. D.; BATISTA, R. O.; COSTA, A. G.; CUNHA, R. R.; ANDRADE, A. T. S. Obstrução de gotejadores operando com efluente de laticínios diluído. Revista Brasileira de Agricultura Irrigada, v. 11, n. 4, p. 1517-1527, 2017.

CARVALHO, L. C. C.; COELHO, R. D.; TEIXEIRA, M. B.; SOARES, F. A. L.; CUNHA, F. N.; SILVA, N. F. Tubos gotejadores convencionais submetidos a aplicação de óxido de ferro via água com carga orgânica e sólidos suspensos. Revista Brasileira de Agricultura Irrigada, v. 9, n. 2, p. 32-41, 2015.

FERNANDES, R. K. A.; BATISTA, R. O.; SILVA, S. K. C.; OLIVEIRA, J. F.; PAIVA, L. A. L. Vazão de gotejadores aplicando água residuária da castanha de caju. Irriga, v. 19, n. 4, p. 585-597, 2014.

FREITAS, C. A. S.; NOGUEIRA, L. K. A.; MOREIRA, L. C. J.; FERREIRA, C. S. Desempenho hidráulico de gotejadores sob o tempo de exposição ao esgoto doméstico tratado. Revista Caatinga, Mossoró, v. 28, n. 1, p. 214-219, 2015.

LIU, H.; HUANG, G. Laboratory experiment on drip emitter clogging with fresh water and treated sewage effluent. Agricultural Water Management, v. 96, n. 5, p. 745-756, 2009.

MEDEIROS, P. R. F.; COELHO, R. D.; BARROS, A. C.; MELO, R. F. Dinâmica do entupimento de gotejadores em função da aplicação de carbonato de potássio. Irriga, v. 13, n. 2 , p. $288-297,2008$.

RIBEIRO, P. A. A. et al. Gotejadores submetidos a condições críticas de qualidade da água. Irriga, v. 1, n. 1, ed. esp., p. 368-379, 2012. 
RICE, E. W.; BAIRD, R. B.; CLESCERI, A. D. Standard methods for the examination of water and wastewater. 22. ed. Washington: APHA: AWWA: WPCR, 2012. $1496 \mathrm{p}$.

SILVA, K. B.; SILVA JÚNIOR, M. J.; BATISTA, R. O.; SANTOS, D. B.; BARBOSA FILHO, S. Desempenho de gotejadores operando com efluente da castanha de caju sob distintas pressões de serviço. Revista Ceres, v. 60, n. 3, p. 339-346, 2013.

SONG, P.; LI, Y.; ZHOU, B.; ZHOU, C.; ZHANG, Z.; LI, J. Controlling mechanism of chlorination on emitter bio-clogging for drip irrigation using reclaimed water. Agricultural Water Management, v. 184, n. 1, p. 36-45, 2017.

TRIPATHI, V. K.; RAJPUT, T. B. S.; PATEL, N. Biometric properties and selected chemical concentration of cauliflower influenced by wastewater applied through surface and subsurface drip irrigation system. Journal of Cleaner Production, v. 139, n. 1, p. 396-406, 2016

Recebido em: 25/03/2017

Aceito em: 01/02/2019 